\title{
Essential fatty acid treatment - effects on nerve conduction, polyol pathway and axonal transport in streptozotocin diabetic rats
}

\author{
D. R. Tomlinson ${ }^{1}$, J.P.Robinson ${ }^{2}$, A. M.Compton ${ }^{2}$ and P. Keen ${ }^{3}$ \\ ${ }^{1}$ Department of Pharmacology, Medical College of St. Bartholomew's Hospital, London, \\ ${ }^{2}$ Department of Physiology and Pharmacology, University of Nottingham, Nottingham, and \\ ${ }^{3}$ Department of Pharmacology, University of Bristol, Bristol, U.K.
}

\begin{abstract}
Summary. This study was designed to examine the effect of dietary supplementation with essential fatty acids (evening primrose oil - 5\% weight:weight added to the diet) on acute neurophysiological and neurochemical defects in streptozotocin-diabetic rats. Diabetic rats, which were not given evening primrose oil, showed highly significant elevations of nerve sorbitol and fructose combined with a depletion of nerve myo-inositol. In those animals there was also a $40 \%$ reduction $(p<0.02)$ in the accumulation of axonally transported substance P-like immunoreactivity proximal to a $12 \mathrm{~h}$ sciatic nerve ligature together with reduced motor nerve conduction velocity $(13 \%[p<0.001]$ and $20 \%[p<0.001]$ in two separate
\end{abstract}

experiments). Treatment of other diabetic rats with evening primrose oil prevented completely the development of the motor nerve conduction velocity deficit without affecting sorbitol, fructose or myo-inositol levels or the deficit in axonal transport of substance P. In a second experiment, treatment of diabetic rats with evening primrose oil was associated with significant attenuation of the conduction velocity deficit, but not complete prevention.

Key words: Diabetes mellitus, diabetic neuropathies, essential fatty acids, axonal flow, substance $P$, nerve conduction, myoinositol, sorbitol, streptozotocin, rat.
The availability of potent, selective inhibitors of aldose reductase has enabled simple experiments to determine whether various defects of nerve function, characteristic of experimental diabetes, are associated with exaggerated flux through the sorbitol pathway. In some instances this association has been refined to indicate an involvement of myo-inositol depletion, itself derived from polyol pathway flux. Thus, the acute slowing of nerve conduction, which is a reproducible phenomenon in diabetic rats, may be prevented by aldose reductase inhibitors [1-3] or by treatment with myo-inositol [4-6]. In either case the treatment maintains levels of nerve free myo-inositol in the normal range. The only other reports of prevention of the conduction deficit in diabetic rats have used intensive insulin treatment and again, where measured, nerve myo-inositol levels were normalised [4]. This defect, therefore, seems to be related to the availability of adequate levels of free myo-inositol in the nerve, with a possible involvement of impaired synthesis and turnover of inositol-containing membrane lipids $[7,8]$.

Other defects do not seem to be clearly related to myo-inositol or to sorbitol pathway metabolites. Pragmatic assessment, by testing the effect of aldose reduc- tase inhibitors on particular defects, has led to the following conclusions. Slow anterograde axonal transport of 6-phosphofructokinase activity is deficient in diabetic rats, this deficit is prevented by intensive insulin treatment [9], but is unaffected by treatment with either of two structurally-unrelated aldose reductase inhibitors [9, 10]. Fast anterograde axonal transport of substance $\mathrm{P}$ is also deficient in rats with streptozotocininduced diabetes mellitus of either 3 weeks' [11] or 9 months' [12] duration. In both cases aldose reductase inhibition attenuated, but did not prevent the deficit, however the deficit was absent in diabetic rats treated with both insulin and an aldose reductase inhibitor [11].

It appears, therefore, that some dysfunctions are entirely related to the sorbitol pathway, others entirely unrelated and one defect of established mixed aetiology.

A search of the literature for other potentially influential disorders of biochemistry in diabetes indicates a possible importance for defects of metabolism of essential fatty acids, with particular reference to gammalinolenic acid and its metabolic products. Thus, there are abnormalities of essential fatty acids in various tissues in both clinical and experimental diabetes [13-15]. Furthermore, treatment of patients [16] or diabetic rats 
Table 1. Experiment 1 - body weight changes, final plasma glucose, motor nerve conduction velocity (MNCV) and axonal transport of substance P-like immunoreactivity (SPLI)

\begin{tabular}{|c|c|c|c|c|c|c|}
\hline \multirow[t]{2}{*}{ Group [n] } & \multicolumn{2}{|c|}{ Body weight [g] } & \multirow{2}{*}{$\begin{array}{l}\text { Blood glucose } \\
{[\mathrm{mmol} / \mathrm{l}]}\end{array}$} & \multirow{2}{*}{$\begin{array}{l}\mathrm{MNCV} \\
{[\mathrm{m} / \mathrm{s}]}\end{array}$} & \multicolumn{2}{|l|}{ SPLI [pg] } \\
\hline & Start & End & & & Background & Proximal accumulation \\
\hline $\begin{array}{l}\text { Control }^{\mathrm{a}} \text { Rats }(7) \\
\text { Diabetic }^{\mathrm{a}} \text { Rats }(8) \\
\text { Control Rats GLA treated (7) } \\
\text { Diabetic Rats GLA treated (8) }\end{array}$ & $\begin{array}{l}288 \pm 3 \\
288 \pm 3 \\
288 \pm 4 \\
292 \pm 3\end{array}$ & $\left.\begin{array}{l}312 \pm 6 \\
225 \pm 4 \\
322 \pm 7 \\
241 \pm 11\end{array}\right] d$ & $\left.\begin{array}{r}4.8 \pm 0.1 \\
25.4 \pm 0.6\end{array}\right] \mathrm{d}$ & 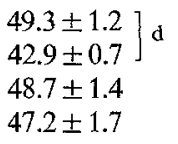 & $\begin{array}{l}303 \pm 41 \\
245 \pm 27 \\
322 \pm 42 \\
256 \pm 48\end{array}$ & 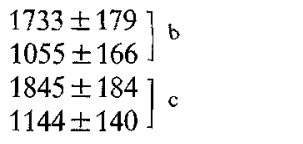 \\
\hline
\end{tabular}

${ }^{a}$ These groups received an olive oil supplement (see Methods). GLA = Gamma-linolenic acid. Data are mean \pm SEM. Significance of differences was assessed by unpaired t tests $;{ }^{\mathrm{b}} p<0.02,{ }^{\mathrm{c}} p<0.01,{ }^{\mathrm{d}} p<0.001$

[17] with a preparation rich in gamma-linolenic acid is reported to ameliorate various aspects of diabetic neuropathy. The present study was, therefore, designed to examine the effect of a dietary supplement of essential fatty acids on defects of nerve biochemistry and function in diabetic rats. The supplement comprised evening primrose (Oenethera biennis) oil. The defects studied were motor nerve conduction velocity (as an example of sorbitol-related dysfunction), axonal transport of substance $P$ (as an example of mixed aetiology) and nerve levels of sorbitol pathway metabolites and myo-inositol.

\section{Materials and methods}

\section{Experimental organisation}

This study comprised two self-contained experiments. Both used male Wistar rats (weight range - 300 to $320 \mathrm{~g}$; age 16-18 weeks) obtained from, and bred in, the Animal Unit, Queen's Medical Centre, Nottingham, U.K. In designated groups diabetes was induced by intraperitoneal streptozotocin $(50 \mathrm{mg} / \mathrm{kg}$ in saline; $0.09 \% \mathrm{NaCl})$, administered after an overnight fast. Two days later the streptozotocin-treated rats were monitored for blood glucose by tail prick and a strip-operated reflectance meter ('Reflolux II'; Boehringer, Mannheim, FRG). Rats with blood glucose values $<15 \mathrm{mmol} / 1$ were rejected from the study. Age-matched controls were given contemporary saline $(0.09 \% \mathrm{NaCl})$ injections and maintained under conditions identical to the diabetic rats. All animals were studied at week 4 of diabetes duration.

In the first experiment 4 groups were studied; two diabetic and two non-diabetic. One group of each was fed a diet containing evening primrose oil ("Efamol"; Efamol Ltd., Guildford, Surrey, U.K.), which was mixed with powdered diet (Heygates 41B (Modified); L.A.

Table 2. Experiment 1 - sciatic nerve contents of monosaccharides and polyols

\begin{tabular}{|c|c|c|c|c|}
\hline \multirow[t]{2}{*}{ Group [n] } & \multicolumn{4}{|c|}{ Sciatic nerve content [nmol $/ \mathrm{mg}$ wet nerve] } \\
\hline & Glucose & Sorbitol & Fructose & myo-Inositol \\
\hline $\begin{array}{l}\text { Control }^{\mathrm{a}} \text { Rats (7) } \\
\text { Diabetic }^{\mathrm{a}} \text { Rats (8) }\end{array}$ & $\left.\begin{array}{r}1.2 \pm 0.2 \\
11.5 \pm 1.1\end{array}\right] \mathrm{c}$ & $\left.\begin{array}{l}0.3 \pm 0.1 \\
3.0 \pm 0.1\end{array}\right] \mathrm{c}$ & $\left.\begin{array}{l}0.1 \pm 0.1 \\
5.9 \pm 0.4\end{array}\right] \mathrm{c}$ & $\left.\begin{array}{l}4.1 \pm 0.5 \\
2.5 \pm 0.1\end{array}\right] b$ \\
\hline $\begin{array}{l}\text { Control Rats (7) } \\
\text { GLA treated }\end{array}$ & $1.6 \pm 0.2$ & $0.2 \pm 0.1] \mathrm{c}$ & $\pm 0.1]$ & \pm 0.4 \\
\hline $\begin{array}{l}\text { Diabetic Rats }(8) \\
\text { GLA treated }\end{array}$ & $9.9 \pm 0.9$ & $2.3 \pm 0.2]^{\circ}$ & $5.8 \pm 0.7$ & $2.5 \pm 0.2$ \\
\hline
\end{tabular}

${ }^{a}$ These groups received an olive oil supplement. GLA $=$ Gamma-linolenic acid. Data are mean $\pm S E M$. Significance of differences (unpaired $t$ tests) were ${ }^{b} p<0.01 ;{ }^{c} p<0.001$
Pilsbury, Northampton, U.K.) to comprise $5 \%$ by weight. The other two groups were given the same rat diet with added olive oil (to $5 \%$ ) to control for the increased fat intake. In each case the oil-enriched diet was mixed thoroughly and pelleted. Feeding with these diets was begun on the day of injection of streptozotocin and maintained throughout the protocol.

On the penultimate day of the protocol all rats were anaesthetised with halothane $\left(2-4 \%\right.$ in $\left.\mathrm{O}_{2}\right)$ for measurement of distal motor latency followed by constriction of the left sciatic nerve to arrest axonal transport of substance $P$ (see below for details). Twelve hours later the rats were killed and both sciatic nerves removed for assay of substance $P$ like immunoreactivity and measurement of sugars and polyols in the unconstricted nerve (see below).

The second experiment was a repeat of part of the first. It comprised three groups - untreated control rats, untreated diabetic rats (both fed a normal diet) and diabetic rats fed a diet containing 5\% evening primrose oil; olive oil was not used. In this study measurements were restricted to motor netve conduction velocity and nerve contents of glucose, sorbitol, fructose and myo-inositol.

\section{Motor nerve conduction velocity}

The method for measurement of distal motor latency is described in detail elsewhere [5]. In the present study this method was adopted exactly as previously described except that a microthermocouple, connected to a digital electronic thermometer (Comark Electronics, Rustington, Sussex, U.K.) was inserted into the sciatic fossa to measure the temperature of the mid-femoral portion of the nerve. The rat was warmed with infra-red lamp and distal motor latency measured at $36^{\circ} \mathrm{C}$. Nerve length, separating the two cathodal stimulation points (sciatic notch and Achilles tendon) was measured on the cadaver, after exposure of the whole nerve, using Vernier calipers.

\section{Axonal transport of substance $P$}

The method is described exactly elsewhere $[11,12]$ and was used here without modification. In previous studies the velocity of axonal transport of substance $\mathbf{P}$ was found to be unaltered in diabetic rats, whilst the amount in transit was reduced. The latter was reflected as a decrease in the material accumulating proximal to a $12 \mathrm{~h}$ constriction applied to the sciatic nerve. Thus, the present study measured this accumulation. The portions of nerve proximal to the constrictions were divided into $5 \mathrm{~mm}$ segments, each of these was extracted and assayed for substance P-like immunoreactivity by radioimmunoassay exactly as described elsewhere $[11,12]$.

\section{Statistical analysis}

All data are presented as arithmetic mean \pm SEM. Group means were compared by unpaired t-tests as is indicated in the tables. 


\section{Results}

\section{General state of the rats}

One of the streptozotocin-treated rats showed sub-threshold hyperglycaemia and was rejected after primary blood glucose screening (see Methods). The remainder were adequately diabetic and one animal died of suspected ketacidosis 3 days after treatment.

All diabetic rats showed marked weight loss and hyperglycaemia at the end of the protocol (Tables 1 and 3 ). In neither experiment was there any indication of an effect of treatment with evening primrose oil on body weight or blood glucose. We conclude that this treatment did not attenuate the general severity of diabetes mellitus.

\section{Nerve sugars and polyols}

Data are shown in Tables 2 and 4. Diabetic rats showed characteristic elevations of nerve glucose, sorbitol and fructose together with depletions of myo-inositol. None of these changes was altered in the diabetic rats fed with evening primrose oil. Likewise, there was no indication of an effect of this treatment on the levels of sugars or polyols measured in the nerves of non-diabetic rats.

\section{Motor nerve conduction velocity}

In both experiments diabetic rats, whether treated with olive oil or fed an unadulterated diet, showed significant reductions in motor nerve conduction velocity. In experiment 1 , the deficit in conduction velocity was absent in the group of diabetic rats treated with evening primrose oil; in experiment 2 , the deficit was significantly attenuated in the diabetic group given evening primrose oil. (see Tables 1 and 3).

\section{Axonal transport of substance $P$}

The accumulation of substance P-like immunoreactivity proximal to $12 \mathrm{~h}$ sciatic nerve constrictions was significantly reduced in olive oil-treated diabetic rats compared to their controls; this accumulation was also reduced in the diabetic rats given evening primrose oil when compared with their controls (see Table 1). The content of substance P-like immunoreactivity in segments of unconstricted nerve was also numerically reduced in both diabetic groups, but these changes did not attain statistical significance.

\section{Discussion}

The findings of this study are clear. Diabetic rats showed a series of peripheral nerve changes which have been well characterized in other studies (see [1-6, 11, $12])$; these were accumulation of sorbitol pathway me-
Table 3. Experiment 2 - body weight changes, final plasma glucose and motor nerve conduction velocity (MNCV)

\begin{tabular}{|c|c|c|c|c|}
\hline \multirow[t]{2}{*}{ Group [n] } & \multicolumn{2}{|c|}{ Body weight [g] } & \multirow{2}{*}{$\begin{array}{l}\text { plasma } \\
\text { glucose } \\
{[\mathrm{mmol} / 1]}\end{array}$} & \multirow{2}{*}{$\begin{array}{l}\mathrm{MNCV} \\
{[\mathrm{m} / \mathrm{s}]}\end{array}$} \\
\hline & Start & End & & \\
\hline Control Rats (8) & $320 \pm 6$ & $353 \pm 7$ & $5.6 \pm 1.7$ & $53.4 \pm 1.4$ \\
\hline Diabetic Rats (7) & $318 \pm 5$ & $259 \pm 11$ & $32.8 \pm 2.0$ & $42.4 \pm 0.5$ \\
\hline $\begin{array}{l}\text { Diabetic Rats (9) } \\
\text { GLA-treated }\end{array}$ & $323 \pm 5$ & $255 \pm 9$ & $34.8 \pm 3.0$ & $48.6 \pm 1.4$ \\
\hline
\end{tabular}

Data are mean \pm SEM. GLA $=$ Gamma-linolenic acid. Significance of differences (unpaired $t$-tests), ${ }^{a} p<0.001$ (massive differences not tested)

Table 4. Experiment 2 - sciatic nerve contents of monosaccharides and polyols

\begin{tabular}{lccll}
\hline Group [n] & \multicolumn{4}{c}{ Sciatic nerve content [nmol/mg wet nerve] } \\
\cline { 2 - 5 } & Glucose & Sorbitol & Fructose & myo-Inositol \\
\hline Control Rats (8) & $2.2 \pm 0.3$ & $0.3 \pm 0.1$ & $0.9 \pm 0.3$ & $4.5 \pm 0.4$ \\
Diabetic Rats (7) & $12.2 \pm 2.0^{\mathrm{a}}$ & $2.8 \pm 0.2^{\mathrm{a}}$ & $5.4 \pm 0.4^{\mathrm{a}}$ & $2.6 \pm 0.2^{\mathrm{a}}$ \\
$\begin{array}{l}\text { Diabetic Rats (8) } \\
\text { GLA-treated }\end{array}$ & $13.6 \pm 1.3^{\mathrm{a}}$ & $3.2 \pm 0.3^{\mathrm{a}}$ & $6.4 \pm 0.6^{\mathrm{a}}$ & $2.9 \pm 0.3^{\mathrm{a}}$ \\
\hline
\end{tabular}

Data are mean \pm SEM. GLA $=$ Gamma-linolenic acid. Significance of differences (unpaired t-tests) were ${ }^{a} p<0.001$ vs equivalent control mean

tabolites, depletion of myo-inositol, reduced accumulation of axonally transported substance P-like immunoreactivity and a deficit in motor nerve conduction velocity. Before discussing the effect of the treatment studied, it is important to consider the possibility that defects in the diabetic rat may be related to an effect of streptozotocin which is distinct from the diabetes it generates. This possibility can be evaluated pragmatically, by examining the extent to which the neurological defects in diabetic rats can be reversed by fine control of glycaemia using insulin. As is indicated in the Introduction, all the defects studied here have been prevented by either insulin alone or by a combination of insulin and an aldose reductase inhibitor (see $[4,5,11,18]$ ).

Of the defects referred to above, only the conduction velocity deficit was affected by treatment with evening primrose oil, in that the two separate treated groups of diabetic rats gave motor nerve conduction velocity measurements, which were not significantly different from the values in their control groups. To our knowledge this is the first time that the acute conduction deficit has been prevented by treatment of diabetic rats when the treatment has not normalised nerve myoinositol levels. This finding surprised us and it was this that motivated the second experiment to remove all doubt about the veracity of the findings from the first experiment. Previous manipulations to prevent the acute conduction deficit have been tight control of blood glucose $[4,18]$, administration of aldose reductase inhibitors $[1-3,5,6]$ or administration of myo-inositol itself $[4,5]$. In the latter two cases nerve myo-inositol le- 
vels have been measured and their normality related to abolition of the conduction deficit $[4,5]$. In the case of insulin treatment normal nerve myo-inositol levels have been registered when this measurement has been included in the study $[4,9]$, so that, even when the measurement has not been made, it is likely that the treatment prevented or attenuated myo-inositol depletion. This association had led to the assumption that the level of nerve myo-inositol effectively limits the maintenance of normal conduction velocity in experimental diabetes (see [7, 8], for example). Hypotheses have developed suggesting that depletion of myo-inositol restricts the synthesis of inositol-containing membrane phospholipids, this reduces the turnover of these lipids and thereby down-regulates processes which are dependent upon their second messenger function $[7,8]$. The exact chain of events whereby these processes are connected to nerve conduction remains a matter for speculation. However, the experiments described in this study demand that this hypothesis be modified.

Evening primrose oil is rich in the essential fatty acids oleic, linoleic and gamma-linolenic acid [19]. Further experiments are needed to define which of these is the critical agent in the treatment, but evidence from other studies [13, 20-22] indicates that gamma-linolenic acid is of potential importance. The metabolism of gamma-linolenic acid in peripheral nerve has not been studied in either normal or diabetic animals. However, information from other tissues indicates that treatment with essential fatty acids can promote conversion of gamma-linolenic acid to arachidonic acid [14, 23, 24]. This, in turn, could boost synthesis of the lipid precursors of inositol-containing phospholipids via conversion of arachidonate to phosphatidic acid and cytosine diphosphate-diacyl glycerol [25]. Thus, the hypothesis stated earlier may be modified to suggest that synthesis of inositol-containing phospholipids may be restricted by deficiencies of both free inositol and the diacyl glyceride moeity and that supplementation of either could restore the balance. Alternatively, it is possible that arachidonate or its fatty acid precursors could activate protein kinase $C[25,26]$ independently of breakdown products of inositol-containing lipids. Such a mechanism could exert a tonic activation of protein kinase $\mathrm{C}$, but the interaction of such an effect with any biochemical parameter of electrical activation of the nerve remains to be elucidated.

A separate possibility might be based on production of prostaglandin $E_{1}$ from gamma-linolenic acid [23, 24]. Again, this has not been demonstrated in peripheral nerves, but it is an established phenomenon in vascular tissue where the cell types responsible for the conversion remain to be identified [27]. Prostaglandin $\mathrm{E}_{1}$ so formed might also modulate biochemical events in the nerve cell membrane favouring nerve conduction, might release other mediators with similar effects or it might act as a vasodilator in the endoneurium - again either directly or indirectly - to preclude the development of ischaemic endoneurial hypoxia [28]. A recent study has shown that a structural analogue of prostaglandin $\mathrm{E}_{1}$ can prevent the acute deficit in motor nerve conduction velocity when administered to streptozotocin-diabetic rats [29]. The mechanism remains to be elucidated, but the finding supports a possible involvement of prostaglandin $E_{1}$ in the effect of essential fatty acids.

Clearly, more incisive studies are warranted. The present findings receive support, in underlining the importance of future work, from clinical studies indicating potential benefits of essential fatty acids in the prevention of diabetic [16, 30] and other forms [31,32] of neuropathy.

Acknowledgements. This work was partially funded by Scotia Pharmaceuticals. We thank Dr. David Horrobin for his interest and support and Miss Carol Brown for typing the manuscript.

\section{References}

1. Tomlinson DR, Holmes PR, Mayer JH (1982) Reversal, by treatment with an aldose reductase inhibitor, of impaired axonal transport and motor nerve conduction velocity in experimental diabetes mellitus. Neurosci Lett 31: 189-193

2. Yue DK, Hanwell MA, Satchell PM, Turtle JR (1982) The effect of aldose reductase inhibition on motor nerve conduction velocity in diabetic rats. Diabetes 31: 789-794

3. Finegold D, Lattimer SA, Nolle S, Bernstein M, Greene DA (1983) Polyol pathway activity and myo-inositol metabolism. A suggested relationship in the pathogenesis of diabetic neuropathy. Diabetes 32: 988-992

4. Greene DA, De Jesus PVJr, Winegrad AI (1975) Effects of insulin and dietary myoinositol on impaired peripheral motor nerve conduction velocity in acute streptozotocin diabetes. J Clin Invest 55: 1326-1336

5. Mayer JH, Tomlinson DR (1983) Prevention of defects of axonal transport and nerve conduction velocity by oral administration of myo-inositol or an aldose reductase inhibitor in streptozotocindiabetic rats. Diabetologia 25: 433-438

6. Gillon KR, Hawthorne JN, Tomlinson DR (1983) Myo-inositol and sorbitol metabolism in relation to peripheral nerve function in experimental diabetes in the rat: the effect of aldose reductase inhibition. Diabetologia 25:365-371

7. Winegrad AI, Simmons DA, Martin DB (1983) Has one diabetic complication been explained? N Engl J Med 308: 152-154

8. Greene DA, Lattimer S, Ulbrecht J, Carroll P (1985) Glucose-induced alterations in nerve metabolism: current perspective on the pathogenesis of diabetic neuropathy and future directions for research and therapy. Diabetes Care 8: 290-299

9. Willars GB, Calcutt NA, Tomlinson DR (1987) Reduced anterograde and retrograde accumulation of axonally transported phosphofructokinase in streptozotocin-diabetic rats: effects of insulin and the aldose reductase inhibitor 'Statil'. Diabetologia 30: 239-243

10. Tomlinson DR, Willars GB, Calthrop-Owen EF (1987) Defects of axonal transport in experimental diabetes that are unrelated to the sorbitol pathway. Exp Neurol 96: 194-202

11. Tomlinson DR, Robinson JP, Willars GB, Keen P(1988) Deficient axonal transport of substance $P$ in streptozocin-induced diabetic rats. Effects of sorbinil and insulin. Diabetes 37:488-493

12. Robinson JP, Willars GB, Tomlinson DR, Keen P (1987) Axonal transport and tissue contents of substance $P$ in rats with long-term streptozotocin-diabetes. Effects of the aldose reductase inhibitor 'statil'. Brain Res 426: 339-448

13. Cunnane SC, Manku MS, Horrobin DF (1985) Abnormal essential fatty acid composition of tissue lipids in genetically diabetic 
mice is partially corrected by dietary linoleic and gamma-linolenic acids. Br J Nutr 53: 449-458

14. Poisson JP, Blond JP(1985) Effect of streptozotocin diabetes upon in vivo conversion of $\mathrm{C}_{14}$ gamma-linolenic and dihomogammalinolenic acids into arachidonic acid in kidneys and whole rat. Diabetic Med 11: 289-294

15. Blaton V, Muis E, Hollez D, Laskeman G, Lambergits G, Herman A, Crief A, Deleclerq B (1988) Dietary influences of evening primrose oil on serum lipids, prostaglandins and platelet function in non-insulin dependent diabetics. J Clin Chem Clin Biochem 26: 286-292

16. Jamal GA, Carmichael H, Weir AI (1986) Gamma-linolenic acid in diabetic neuropathy. Lancet I: 1098

17. Horrgbin DF, Julu PO, Jamal GA (1988) Gamma linolenic acid as a treatment for diabetic neuropathy and other diabetic complications. Diabetes Res Clin Pract [Suppl 1] 5: S57-S57 (Abstract)

18. Mayer JH, Tomlinson DR (1983) Axonal transport of cholinergic transmitter enzymes in vagus and sciatic nerves of rats with acute experimental diabetes mellitus; correlation with motor nerve conduction velocity and effects of insulin. Neuroscience 9: 951-957

19. Manku MS (1983) A comparison of gas liquid chromatography and high performance liquid chromatography methods for determining fatty acid composition of evening primrose (Oenothere biennis) and soyabean oil. J Chromatog Sci 21:367-369

20. Garcia PT, Holman RT (1985) Competition inhibitions in the metabolism of polyunsaturated fatty acids studied via the composition of phospholipids, triglycerides and cholesteryl esters of rat tissues. J Am Oil Chem Soc 42: 1137-1141

21. Cunnane SC, Manku MS, Horrobin DF (1985) Essential fatty acids in the liver and adipose tissue of genetically obese mice: effect of supplemental linoleic and gamma-linolenic acids. $\mathrm{Br} \mathrm{J}$ Nutr 53: $441-448$

22. Chaintreiul J, Monnier L, Colette C, Crastes de Paulet P, Orsetti A, Spielmann D, Mendy F, Crastes de Paulet A (1984) Effects of dietary gamma-linolenate supplementation on serum lipids and platelet function in insulin-dependent diabetic patients. Human Nut Clin Nut 38C: $121-130$

23. Horrobin DF, Manku MS, Huang YS (1984) Effects of essential fatty acids on prostaglandin biosynthesis. Biomed Biochim Acta 43: $\mathrm{S} 114-\mathrm{S} 120$

24. Larsson-Backstrom C, Arrhenius E, Sagge K, Lindmark L, Svensson L (1986) Influence of alpha-linolenic and gamma-linolenic acid enriched and fat free diets on fatty acid profile and prostaglandin biosynthesis and on the outcome of rat intraperitoneal sepsis. Prog Lipid Res 25: 197-210

25. Simmons DA, Winegrad AI, Martin DB (1982) Significance of tissue myo-inositol concentrations in metabolic regulation in nerve. Science 217: 848-851

26. Ashendel CL (1985) The phorbol ester receptor: a phospholipidregulated protein kinase. Biochim Biophys Acta 822: 219-242

27. Watanabe Y, Manku MS, Jendins DK, Mitchell J, Horrobin DF (1987) The effects of short term dietary supplementation with evening primrose oil or safflower oil on fatty acid and prostaglandin release from perfused mesenteric vascular beds in spontaneously hypertensive rats. J Am Coll Nutr 6: 447-453

28. Tuck RR, Schmelzer JD, Low PA (1984) Endoneurial blood flow and oxygen tension in the sciatic nerves of rats with experimental diabetic neuropathy. Brain 107: 935-950

29. Yasuda H, Sonobe M, Hatanaka I, Yamashita M, Miyamoto Y, Terada M, Amenomori M, Kikkawa R, Shigeta Y, Motoyama Y (1988) A new prostaglandin E1 analogue (TFC-612) prevents a decrease in motor nerve conduction velocity in streptozocin-diabetic rats. Biochem Biophys Res Commun 150: 225-230

30. Horrobin DF, Botez T, Botez MI (1979) Polyunsaturated fatty acids and colchicine in multiple sclerosis. Br Med J 1: 199-200

31. Horrobin DF (1988) The roles of essential fatty acids in the development of diabetic neuropathy and other complications of diabetes mellitus. Prostaglandins Leukotrienes Essen Fatty Acids 31: 181-197

32. Williams LL, O'Dougherty MM, Wright FS, Bodulski RJ, Horrocks LA (1986) Essential fatty acid dietary addition in hereditary neuropathy. Prog Lipid Res 25:607-610

Received: 3 March 1989

and in revised form: 30 May 1989

Prof. D. R. Tomlinson

Department of Pharmacology

Medical College of St. Bartholomew's Hospital

Charterhouse Square

London EC1M 6BQ

UK 